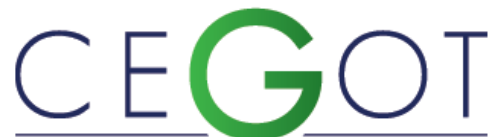

Centro de Estudos de Geografia e Ordenamento do Território
Geografia e Ordenamento do Território, Revista Eletrónica Centro de Estudos de Geografia e Ordenamento do Território http://cegot.org ISSN: 2182-1267

\author{
ZOUAIN, DEBORAH \\ Universidade do Grande Rio - UNIGRANRIO \\ 25071-202, Rio de Janeiro, Brasil \\ deborahzouain@gmail.com \\ Pereira, Airton \\ Associação Brasileira das Empresas Aéreas - ABEAR \\ 04028-002, São Paulo, Brasil \\ tompereira@uol.com.br
}

SOUZA, LUIZ

Universidade do Grande Rio - UNIGRANRIO

25071-202, Rio de Janeiro, Brasi

luiz.alexandre.valadao@gmail.com

\section{DUARTE, ANDRÉ}

Comissão Nacional de Energia Nuclear - CNEN

Rua Gal. Severiano, 90, Botafogo, 22290-901, Rio de Janeiro, Brasil

alduarte@cnen.gov.br

\title{
Destinos indutores do turismo brasileiro: um estudo de casos múltiplos
}

\section{Brazilian tourism-inducing destinations: a multiple case study}

Referência: Zouain, Deborah; Pereira, Airton; Souza, Luiz, Duarte, André (2020). Destinos indutores do turismo brasileiro: um estudo de casos múltiplos. Revista de Geografia e Ordenamento do Território (GOT), n.으 20 (Dezembro). Centro de Estudos de Geografia e Ordenamento do Território, p. 191-220, dx.doi.org/10.17127/got/2020.20.009

\section{RESUMO}

A competitividade das destinações turísticas tem seguido uma lógica de mercado e, apesar do turismo ser um fenômeno complexo com aspectos culturais e sociais relevantes, seu papel na economia dos municípios, e até do país, são cada vez mais significativos. Considerando os aspectos econômicos e a geração de receitas que impactam na balança de pagamentos nacionais, o Ministério do Turismo (Mtur), juntamente com a Fundação Getúlio Vargas (FGV) e o Serviço Brasileiro de Apoio às Micro e Pequenas Empresas (SEBRAE), reuniram esforços para realizar uma pesquisa com o intuito de diagnosticar o panorama de competitividade dos destinos turísticos brasileiros. Os resultados encontrados foram apresentados no "Estudo de Competitividade de 65 Destinos Indutores do Desenvolvimento do Turismo Regional". O objetivo deste trabalho é analisar o efectivo impacto dos resultados deste estudo na agenda do Mtur. Desta forma, foi realizado um estudo de casos múltiplos, por meio do qual se comprovou que os problemas detectados no Estudo não foram priorizados, permanecendo no mesmo patamar dos demais problemas do país. Também ficou claro que não foi estruturada uma solução alinhada às ações do Ministério.

Palavras-chave: políticas públicas, destinos indutores do turismo, turismo, competitividade. 


\section{ABSTRACT}

The competitiveness of tourist destinations has followed a market logic, and although tourism is a complex phenomenon with relevant cultural and social aspects, its role in the economy of municipalities and even the country is increasingly significant. Considering the economic aspects, and the generation of revenues that impact the national balance of payments, the Ministry of Tourism (Mtur), together with the Getúlio Vargas Foundation (FGV) and the Brazilian Service of Support to Micro and Small Companies (SEBRAE) efforts to conduct a survey in order to diagnose the competitive overview of Brazilian tourist destinations. The results found were presented in the "Competitiveness Study of 65 Destinations Inducing the Development of Regional Tourism". The aim of this paper is to analyze the effective impact of the results of this study on the Mtur agenda. Thus, a multiple case study was carried out, through which it was proven that the problems detected in the Study were not prioritized, remaining at the same level as the other problems in the country. It was also clear that a solution in line with the Ministry's actions was not structured.

Keywords: public policies, tourism-inducing destinations, tourism, competitiveness.

\section{Introdução}

O turismo é uma indústria crescente, independente, com grande importância econômica mundial. As atividades turísticas geram movimentos para se concretizar, modificando o panorama local de onde ocorrem com: criação de rede hoteleira, de empresas no ramo da gastronomia e melhorias na prestação de serviços em geral, incluindo os de saúde. Com isso, elas se tornam fonte de emprego e de renda. Os governos, nos âmbitos federal, estadual e municipal, são parte importante nesse contexto, principalmente no que tange à responsabilidade em relação a pontos específicos, como: infraestrutura em todos os seus termos e criação de políticas públicas, ordenação, normalização e controle geral da atividade desenvolvida e outros, nos níveis das respectivas competências.

Desde que o turismo passou a ser considerado um grande fator de crescimento da economia, inclusive sendo chamado de indústria do turismo pela grande movimentação financeira que proporciona e pelo conjunto de elementos que agrega em cadeia, como hotéis, restaurantes e outros, tornou-se possível de ser avaliado por meio de indicadores semelhantes aos de outras áreas do mercado. Um desses indicadores é a competitividade.

A competitividade internacional nos mercados é um tema de grande relevância nas discussões sobre as prioridades públicas em países desenvolvidos e em desenvolvimento. 
Consequentemente, os indicadores de competitividade, representam um elemento importante para a mensuração da sobrevivência e do crescimento de países, empresas ou grupos. Assim, aplicar critérios do indicador de competitividade na análise de destinos turísticos significa dizer, inicialmente, que se está aferindo, com certo rigor (menos subjetividade), suas condições de sobrevivência e crescimento. Também acompanha a tendência mundial contemporânea de mensuração de fenômenos por meio desse indicador. Visando a uma avaliação interna da situação brasileira, em 2008, o Ministério do Turismo, em sua função de articular-se com os demais Ministérios, com os governos estaduais e municipais, com o poder legislativo, com o setor empresarial e a sociedade organizada, entre outros, associou-se à Fundação Getúlio Vargas (FGV) e ao Serviço Nacional de Apoio às Micro e Pequenas Empresas (SEBRAE), para avaliar a competitividade de 65 destinos indutores do desenvolvimento turístico regional, destinos esses previamente selecionados. A finalidade foi identificar aspectos da estrutura desses destinos que necessitassem de apoio governamental, a fim de eles alcançarem padrões internacionais de competitividade.

Desta forma, como processo que inclui a mobilização de atores, recursos e instituições, o desenvolvimento territorial tem condições de incrementar a competitividade de atividades econômicas locais e gerar bem-estar à comunidade desse meio (Ribeiro \& Chamusca, 2020). Vieira, Hoffmann e Alberton (2018) sustentam que uma das formas de se identificar como a competitividade pode ser melhorada, é a partir da análise da influência dos investimentos públicos na competitividade do destino. No entanto, é notório que no Brasil, o aporte de investimentos públicos segue uma lógica complexa, que nem sempre atende aos fundamentos técnicos que deveriam balizar as decisões governamentais.

Sette e Tomazzoni (2017, p. 314) pesquisaram sobre as limitações do Modelo do ìndice de Competitividade Turística, no contexto brasileiro, e afirmam que "os destinos deixaram de ser denominados de indutores, e o Índice de Competitividade Turística passou a ser uma ferramenta apenas de monitoramento ou de diagnóstico para os destinos."

Considerando que a política ligada aos indutores do desenvolvimento turístico foi descontinuada, e que os destinos em condição de competir, foram identificados através de uma metodologia de pontuação, que em teoria forneceram informações fundamentais para a formulação de políticas públicas, bem como para destinação de recursos governamentais, 
a questão principal que se configura como objetivo deste estudo é identificar se a estratégia inicial foi efetivamente seguida.

\section{Referencial Teórico}

A competitividade, pouco relevante na teoria econômica regional tradicional, "é hoje um ponto estratégico de máxima importância para o desenvolvimento endógeno. Ela deixou de pertencer apenas ao mundo das empresas para pertencer também ao mundo das regiões" (Amaral Filho, 2001, p. 279-280). As teorias e as políticas de desenvolvimento regional atualmente buscam uma síntese que integre a organização econômica e a organização setorial à organização territorial. Mas para a manutenção dessa síntese, o desenvolvimento regional endógeno deve refutar o indeterminismo que havia no respectivo processo e pode ser comprovado na história e nas ações dos protagonistas locais. No desenvolvimento regional endógeno, a estrutura inclui atores locais, o que, em relação ao turismo, se coaduna com a descentralização das ações propostas no Programa de Regionalização do Turismo (Amaral Filho, 2001).

Unindo a primeira motivação à segunda, a realização do "Estudo de Competitividade dos 65 Destinos Indutores do Desenvolvimento Turístico Regional" representou uma decisão estratégica do Ministério do Turismo, junto com os parceiros Fundação Getúlio Cargas (FGV) e Serviço Nacional de Apoio às Micro e Pequenas Empresas (SEBRAE), buscando mensurar, por meio do indicador de competitividade especialmente delineado, a relação entre as vantagens competitivas e as vantagens comparativas dos destinos selecionados.

Vale lembrar que as políticas públicas de turismo se constituem na forma pela qual o poder público faz suas intervenções no setor. Com isso, o Estado redefine seu papel perante a atividade turística, tentando agir mais como um elemento regulador da atividade. Para Borges, Ferreira e Nóbrega (2019), a participação do turismo na política pública de uma cidade ocorre em diversos níveis, tanto econômicos quanto sociais, com potencial de gerar desenvolvimento que beneficie turistas e a comunidade local.

A questão que se coloca nesse sentido é entender por que alguns problemas conseguem integrar a agenda de políticas (agenda setting) e, consequentemente, passam a receber 
tratamento mais direto do governo, e outros são ignorados (Souza, 2006, p. 29). Associando o contexto das agendas de políticas - que relaciona problemas com soluções e participações políticas e sociais - ao fenômeno da competitividade - cujo indicador, atualmente, serve de parâmetro para se avaliar o desempenho de países, de empresas ou de grupos em relação a seus pares -, chega-se ao papel do "Relatório Brasil - Estudo de Competitividade dos 65 Destinos Indutores do Desenvolvimento Turístico Regional" e seu potencial para inclusão dos problemas encontrados na agenda de políticas do Ministério do Turismo.

Os destinos turísticos brasileiros são abrangidos por planos e políticas de turismo, e a atividade, por sua característica econômica, deve ser foco de planejamento como qualquer outra, para poder alcançar seus objetivos. O planejamento turístico, desta forma, é elaborado com o objetivo de realizar intervenções e ordenamentos no território, envolvendo o trabalho de equipes multidisciplinares com conhecimento dos elementos que constituem este espaço, sejam materiais ou imateriais, naturais ou produzidos pelo homem (Fratucci \& Moraes, 2020). Para Damas e Brambatti (2019), um planejamento turístico engloba vários fatores, "desde políticas públicas, inclusão de moradores, fatores econômicos, sociais, ambientais e principalmente culturais, no qual todos devem estar inseridos integralmente, visando o pleno desenvolvimento" (pp. 165-166).

Seguindo a lógica de mercado, o turismo passou a ter indicadores de competitividade, e a sua mensuração passou a influenciar políticas públicas no mundo. Afinal, o contexto de desenvolvimento do turismo e a necessidade de se incrementar as capacidades competitivas a ele relacionadas, exigem estratégias específicas (Moyano, Lengler, \& Angnes, 2018).

Hassan (2000) definiu a competitividade do turismo como a capacidade que o destino tem de criar e de integrar valores a produtos, mantendo seus recursos e sua posição no mercado em relação aos concorrentes. Dependendo de vários fatores, o nível de competitividade do turismo deve ser elevado, porque o setor já representa uma das principais atividades econômicas em termos mundiais. Isso faz com que muitos lugares busquem meios de se desenvolver como tal, utilizando-se dos recursos de que dispõem. Neste sentido, Oliveira, Zouain, Souza e Duarte (2019) ressaltam que a experiência do turista pode ser considerada uma variável de desempenho da competitividade do destino. 
Na discussão sobre o assunto, Armenski, Markovic, Davidovic e Jovanovic (2011) defendem que o marco do sucesso dos destinos turísticos no mundo é influenciado por sua competitividade relativa. Uma vantagem competitiva pode ser alcançada se o apelo global do destino for superior àquele de um destino alternativo para os potenciais visitantes. A competitividade dos destinos turísticos não é definida pelo conjunto rígido de recursos naturais, culturais, artísticos ou ambientais, mas sim pelo apelo global do destino. Também leva-se em conta que, para um destino alcançar uma posição favorável no mercado do turismo, deve-se observar se esses recursos são gerenciados adequadamente e se esse destino é capaz de desenvolver vantagens competitivas. Além do dinamismo do setor de turismo, as constantes mudanças do mercado e a acirrada competitividade, mostram o desafio e a necessidade dos gestores desenvolverem recursos estratégicos que promovam o desenvolvimento sustentável (Alvarenga, Leite, Freitas, \& Ruas, 2017). A fim de conseguir resultados apropriados entre recursos turísticos e estratégias de gestão, é necessário que a indústria e o governo compreendam os pontos mais fortes e os mais fracos relacionados à competitividade de seu país em relação aos demais.

Neste sentido, é preocupante o que o Fórum Econômico Mundial divulgou:

O Brasil perdeu posições em um ranking mundial de competitividade no setor do turismo, embora tenha obtido pontuação semelhante à de 2009. Em sua última edição, relativa a 2011, o relatório elaborado pelo Fórum Econômico Mundial coloca a sede da próxima Copa do Mundo e das Olimpíadas de 2016 na posição 52 entre 139 países avaliados. A pontuação, 4,36 em uma escala de um a sete, foi praticamente a mesma que em $2009(4,35)$, quando foi elaborado o ranking anterior mais recente. Naquele ano, quando foram consideradas 133 nações, o país ficou em 45․ Em 2011, o Brasil foi ultrapassado por outros que registraram um incremento mais expressivo, como México e Porto Rico. O Brasil ficou em sétimo lugar no ranking das Américas e 52 ㅇ no ranking geral. O país é o que tem a melhor pontuação entre todos os países no que tange aos recursos naturais e 230 em recursos culturais, com muitos lugares considerados patrimônio da humanidade, uma grande proporção de área protegida e a fauna mais rica do mundo (BBC, 2011, p. 1).

Dwyer e Kim (2003) propõem que em um destino turístico competitivo, três pontos devem ser fundamentalmente considerados: o gerenciamento dos fatores relacionados aos destinos (atividades do setor público e do privado), as condições da demanda (com três principais elementos: percepção, preferências e consciência) e as condições situacionais (econômica, social, cultural, política, legal). Esses pontos podem ser comparados para qualificar e ampliar os determinantes da destinação turística. 
Mas o interesse dos estudiosos sobre o tema, diante da complexidade do conceito de competitividade, principalmente quando aplicado aos destinos turísticos, levou ao desenvolvimento de modelos que buscam aproximar, ainda mais, esse fenômeno da realidade que é ampla e multifatorial.

Para Hassan (2000), um modelo detalhado de competitividade pode se concentrar nos fatores de sustentabilidade ambientais dos destinos de viagem, os quais exigem um modelo de competitividade que analise a relação entre todas as partes envolvidas em seus produtos e no valor agregado. Os destinos turísticos devem primar pelo exame sistemático das vantagens exclusivas de que dispõem, como forma de manter sua longevidade. Eles têm a função de corresponder à procura do mercado e aos desafios da competitividade.

O "Estudo de Competitividade dos 65 Destinos Indutores do Desenvolvimento do Turismo Regional" (MTur, 2008) refere-se aos seguintes modelos de avaliação da competitividade dos destinos turísticos, entre outros: o de Gooroochurn e Sugiyarto (2004), centrado em unidades de análise representadas por países, numa amostra com mais de 200 participantes/nações. O modelo inclui os temas: preços, desenvolvimento tecnológico, desenvolvimento humano para o turismo, abertura econômica, infraestrutura, meio ambiente e recursos humanos; o de Crouch e Ritchie (1999), calcado nos fatores: qualificação, gestão do destino, atrativos e recursos-chave e recursos de apoio, e o de Melián-González e García-Falcón (2003), baseado nos recursos naturais e nos culturais, fundamentalmente.

Este estudo baseou-se em cinco macrodimensões, a saber: infraestrutura, turismo, políticas públicas, economia e sustentabilidade. E estas macrodimensões foram subdivididas em 13 dimensões: acesso, infraestrutura geral, atrativos turísticos, serviços e equipamentos turísticos, marketing, cooperação regional, política pública, monitoramento, economia local, capacidade empresarial, aspectos ambientais, aspectos sociais e aspectos culturais.

Em relação às políticas públicas, semelhante ao que ocorre com a competitividade, ainda não há um conceito fechado pelo fato de elas constituírem um campo relativamente novo da Ciência Política. É certo, porém, que seu objetivo, em termos bem simples, é colocar o governo em ação ou analisar essa ação, propondo ou não mudanças em seu rumo ou curso. Nesse sentido, as decisões governamentais são só incrementais e pouco substantivas, pois 
não partem do zero e resultam de decisões marginais que não consideram grandes mudanças via programas públicos (Souza, 2006).

Em uma retomada das primeiras noções de políticas públicas, Souza (2006) afirma que "os fundadores" dessa área, visando a criar o respectivo conceito, introduziram estas ideias: policy analysis (análise de política púbica) ou a conciliação do conhecimento científico com a produção empírica dos governos (Laswel, 1936); policy makers (decisores políticos) ou a racionalidade limitada dos decisores, principalmente em relação ao conhecimento ou informação para a tomada de decisão (Simon, 1957), entre outras variáveis.

Posteriormente, conceitos foram surgindo, enfocando um ou mais aspectos relacionados com a ideia desses fundadores ou distanciando-se um pouco: "política pública é o que o governo escolhe fazer ou não fazer" (Dye, 1984 apud Souza, 2006, p. 24); "Políticas públicas são resultantes da atividade política, requerem várias ações estratégicas destinadas a implementar os objetivos desejados e constituem-se de decisões e ações que estão revestidas da autoridade soberana do poder público" (Rodrigues, 2011, p. 14).

De acordo com Pimentel e Pimentel (2019), as políticas em turismo se consolidam na agenda pública a partir da década de 1960, formalizando-se no arranjo organizacional estatal, tornando-se prioridade para os governos a partir da dáecada de 1990, passando a pautar-se pela competitividade no mercado turístico globalizado.

\section{Metodologia}

\subsection{Delineamento da pesquisa}

Esta pesquisa utilizou o método de estudo de casos múltiplos, focando nos casos de Ouro Preto, Rio Branco, São Joaquim e Goiânia. Segundo Yin (2015, p. 244), o estudo de caso é "um estudo que investiga um fenômeno contemporâneo em profundidade e em seu contexto de mundo real".

O PNT 2007/2010 embasou o Estudo de Competitividade dos 65 Destinos Turísticos Indutores do Desenvolvimento Regional, e busca a reestruturação de destinos turísticos, através de investimentos governamentais em destinos indutores de desenvolvimento turístico regional. 
Os demais destinos, fora os 65 selecionados, continuaram o processo de organização regional, segundo as diretrizes e módulos operacionais do Programa de Regionalização do Turismo, de modo a estarem fortalecidos para absorção dos impactos trazidos pelo desenvolvimento do turismo em seus territórios.

A mensuração do indicador de competitividade é composto de 13 pilares, e a pontuação foi dividida em cinco escalas de zero a dez, com a seguinte classificação:

O primeiro nível ( 0 a 20 pontos) refere-se ao intervalo em que os destinos apresentam deficiência em relação à determinada dimensão; o segundo nível (21 a 40 pontos), apesar de expor uma situação mais favorável do que o anterior, ainda evidencia níveis inadequados para a competitividade de um destino em relação à dimensão; o terceiro nível (41 a 60 pontos) configura situação regularmente satisfatória; o quarto nível (61 a 80 pontos) revela a existência de condições adequadas para atividades turísticas, e é, neste trabalho, o padrão mínimo de qualidade para a dimensão analisada; e o quinto nível corresponde ao melhor posicionamento que um destino pode alcançar em uma dada dimensão (81 a 100 pontos) (MTur, 2008, p. 65).

Considerando que há uma diferença significativa entre a média obtida pelas capitais brasileiras, que é 59,3 e os destinos que não são capital, que obtém média de 46,7 , observase que as capitais estão com a média acima da média geral do Brasil, que é de 52,0. (MTur, 2008, p. 66). Desta forma, ficou evidenciado que há a necessidade de estímular destinos indutores para que se alcance uma melhoria na competitividade dos destinos brasileiros.

\subsection{Procedimentos de coleta de dados}

A recolha de dados foi feita através de pesquisa documental, no "Estudo de Competitividade dos 65 Destinos Turísticos Indutores do Desenvolvimento Turístico Regional" de 2008, e também foram analisadas as cinco versões posteriores, com a finalidade de identificar melhoria nas dimensões da competitividade nos destinos selecionados para esta pesquisa. Foram analisadas nos documentos consultados: as ações consideradas prioritárias no "Estudo de Competitividade" de 2008 e o dos anos subseqüentes; as ações e prioridades estabelecidas nos PNT de 2003, 2007, 2012; as ações referentes do MTur relativas às Leis de Diretrizes Orçamentárias (LDOs) e à Lei Orçamentária Anual (LOA) de 2008 a 2014; as ações do MTur nos Planos Plurianuais (PPAs) de 2008 e 2011; convênios firmados entre o MTur e os municípios entre 2008 e 2010; 
documento referencial Turismo no Brasil 2011-2014 e documentos diversos com registros de prioridades que comprovassem a relação entre a execução de ações/destinação de recursos, por parte do MTur - nas treze dimensões propostas pelo Estudo de Competitividade - , e a construção da agenda de políticas desse órgão.

Os dados foram coletados no período de junho a agosto de 2015, visando identificar um tratamento governamental prioritário dispensado aos problemas detectados nos destinos incluídos no "Estudo de Competitividade dos 65 Destinos Turísticos Indutores do Desenvolvimento Turístico Regional" de 2008. Os dados foram coletados com base nos seguintes pontos norteadores:

- distribuição dos recursos pelo MTur para os 65 destinos prioritários e não prioritários;

- repasse de recursos para os destinos constantes do "Estudo de Competitividade dos 65 Destinos Turísticos" antes e depois desse estudo;

- repasse de recursos aos 65 destinos conforme os pilares do "Estudo de Competitividade dos 65 Destinos Turísticos Indutores do Desenvolvimento Turístico Regional".

\subsection{Tratamento dos dados}

Os dados compilados nos diversos documentos citados foram, inicialmente, organizados cronologicamente e comparados em relação aos períodos antes e após o "Estudo de Competitividade". Foram associados às respectivas finalidades e destinos turísticos e relacionados aos 13 pilares que compõem o indicador de competitividade.

Por último, buscou-se associar os dados posteriores a 2008 a tratamento prioritários (inclusão na agenda) por parte do MTur, tendo em conta o objetivo do Estudo de Competitividade e verificar melhorias ocorridas nos destinos selecionados em comparação a 2008.

\section{Resultados e discussão}

As análises buscam desenvolver uma visão comparativa do tratamento geral dispensado pelo MTur aos destinos turísticos e, por último, aos quatro destacados nesta pesquisa em 
particular. Para tanto, respectivamente, os resultados foram divididos em: panorama contextual, panorama dos 65 destinos e destinos selecionados e serão apresentados nesta ordem.

Os convênios e contratos de repasse, que são instrumentos que permitem a transferência de recursos voluntários entre o governo federal e os municípios, foram analisados, de forma a correlacionar as ações governamentais (liberação de recursos) a políticas/programas especiais de governo. O período de análise corresponde aos dois anos anteriores, e aos dois posteriores ao Estudo de 2008.

$\mathrm{Na}$ tabela 1, encontra-se o total dos recursos distribuídos aos destinos selecionados no "Estudo de Competitividade dos 65 Destinos Indutores do Desenvolvimento Turístico Regional" e aos demais destinos turísticos nos dois biênios enfocados, bem como o número de contratos e de convênios celebrados nesses períodos. O objetivo é comparar o tratamento prioritário dado aos 65 destinos, diante da finalidade do PNT.

Tabela 1 - Demonstrativo do volume de recursos distribuídos destinos turísticos

\begin{tabular}{lllllll}
\hline Locais & Volume R\$ & Volume R\$ & Var. & Cont./Conv. & Cont./Conv. & Var. \\
\hline & $2006 / 2007$ & $2009 / 2010$ & $\%$ & $2006 / 2007$ & $2009 / 2010$ & $\%$ \\
\hline 65 Destinos & $565.919 .248,30$ & $766.424 .260,30$ & 35,43 & 571 & 639 & 11,91 \\
\hline Outros Destinos & $883.174 .258,00$ & $3.039 .838 .678,00$ & 244,19 & 4229 & 8881 & 110,00 \\
\hline
\end{tabular}

Fonte: Portal da Transparência (2015), adaptada pelos autores.

Analisando esta tabela, fica claro que houve um dispêndio crescente de recursos distribuídos entre Outros Destinos, 296,6\% superior ao dos 65 incluídos no "Estudo de Competitividade". Esta é uma questão emblemática que suscita questionamentos, pois os 65 Destinos foram identificados como destinos indutores do turismo regional. Além disso, observa-se que no período anterior (2006/2007), o volume de recursos dos Outros Destinos havia sido superior ao dos 65 , em cerca de $56 \%$. Quando se analisa o número de convênios e de contratos de repasses firmados no período, também se observa um fato intrigante, pois os 65 Destinos passaram de 571 para 639, ou seja apresentaram uma variação de apenas 11,91\%, enquanto os Outros Destinos passaram de 4229 para 8881, ou seja, apresentaram uma variação de $110 \%$. 
Desta forma, fica evidente que mesmo após os 65 destinos avaliados apresentarem problemas que interferiam em seu nível de competitividade, tornando-se portanto, objeto de tratamento priorítário pelo Mtur, de fato não foi o que ocorreu.

Muito pelo contrário, a liberação de recursos no biênio posterior ao Estudo foi mais de cinco vezes superior à do biênio que o antecedeu. Logo, trata-se de uma relação inversa entre o crescimento da distribuição de recursos pelo Mtur, e a meta do PNT, de estruturação destes destinos.

A meta do PNT era de que 15 dos 65 destinos indutores fossem estruturados até o final de 2008, e alcançassem o padrão de qualidade internacional, por meio do Mtur, e de suas instituições parceiras. Os outros 50 destinos seriam trabalhados de acordo com as metas do PNT 2007/2010. Já o restante dos destinos turísticos do país deveria continuar o processo de organização regional, de conformidade com as diretrizes e módulos operacionais do Programa de Regionalização do Turismo, para "estarem fortalecidos para absorver os impactos do desenvolvimento da atividade em seus territórios, até 2010" (MTur, 2008, p. 18).

A política do MTur, à época, estava traduzida no PNT 2003/2007 e no PNT 2007/2010. O PNT inclui o Programa de Regionalização do Turismo que tem, entre suas finalidades e metas, a "estruturação de roteiros turísticos intermunicipais nas regiões turísticas brasileiras, com base nos princípios da cooperação, integração e sustentabilidade ambiental, econômica, sociocultural e político-institucional", com metas a serem atingidas até 2010 (MTur, 2008, p. 17). Os objetivos desses programas deveriam responder pela finalidade da aplicação desses recursos nos respectivos destinos. E por esta razão estes PNTs foram selecionados, pois desta forma foi possível analisar o cenário anterior ao Estudo de Competitividade dos 65 Destinos Turísticos Indutores, e suas influências no PNT subsequente.

O índice geral resume a pontuação de cada uma das três dimensões avaliadas pelo Estudo modelo de regulação, ambiente de negócios e infraestrutura e recursos humanos, naturais e culturais. Esse indicador foi especialmente construído pelos consultores representantes do MTur, FGV e SEBRAE, órgãos parceiros realizadores da pesquisa. Sobre a metodologia do Estudo, foi utilizada a metodologia da pontuação, a qual permitiria identificar os pontos 
fortes e os pontos fracos de cada destino, bem como seu posicionamento relativo ante os demais. Esse quadro iria servir de "subsídio para o estabelecimento de políticas públicas de alocação de recursos para consolidação do processo de competitividade dos destinos em questão" (MTur, 2008, p. 31).

Os destinos turísticos com melhor pontuação relativa à competitividade, bem como os de menor pontuação, encontram-se distribuídos nas cinco regiões, entre capitais e não capitais e entre os vários tipos de atividade turística. A falta de concentração dessa pontuação (maior ou menor) em uma região ou em uma atividade turística específica significa que há deficiências generalizadas no desenvolvimento do turismo no Brasil, tanto nas capitais como nas não capitais. Não se trata, pois, de eficiências pontuais, típicas do lugar ou do desenvolvimento de uma atividade turística específica.

Sabe-se que 37 destinos receberam mais recursos após o "Estudo de Competitividade", enquanto 28 receberam menos. Se se considerar a quantidade de convênios e contratos de repasses, 32 destinos assinaram mais após o Estudo; cinco mantiveram o número, e 28 assinaram menos convênios. Houve um total de 639 entre convênios e termos de parceria firmados em 2009/2010, contra 571, em 2006/2007, numa diferença de 68 projetos.

No total de recursos recebidos, houve um crescimento de $35,43 \%$, totalizando $R \$$ 766.424.26039 no biênio 2009/2010, contra R\$ 565.919.248,30 do biênio 2006/2007.

Em alguns destinos, vê-se (nas tabelas 2 e 3) uma relação direta entre índices mais baixos de competitividade e aumento dos recursos após o Estudo como por exemplo São Raimundo Nonato, Tibau do Sul e outros, concomitantemente à relação inversa entre indicadores também mais baixos e variação negativa de recursos recebidos (Aracati, Ipojuca e outros).

Isso pode demonstrar que, quantitativamente, a liberação de recursos para mais ou para menos não atendeu a uma lógica de maior ou de menor necessidade demonstrada pela pontuação de competitividade no Estudo. Qualitativamente, a questão que fundamentou o PNT foi tornar os 65 destinos com melhores condições de competir.

Ao mesmo tempo, como não se identificou a criação de nenhum programa ou plano especial posteriormente ao "Estudo de Competitividade", entende-se que a liberação de recursos para esses destinos estava atrelada ao PNT, tal como estão os destinos que não integram o grupo dos 65. 
Com isso, depreende-se que não houve tratamento diferenciado na política do MTur para os 65 destinos em relação aos demais, já que, pelos documentos pesquisados, os problemas detectados no Estudo não integraram nenhuma pauta especial, programa ou agenda de política do órgão.

A constatação de que não houve tratamento diferenciado dos 65 destinos leva a dois entendimentos: primeiro, que o resultado do citado Estudo não foi considerado como deveria pelo MTur, órgão do governo detentor dos recursos para solução dos problemas. Isso confirma as palavras de Vieira (2011), no sentido de que a incorporação de políticas públicas às estratégias do setor por parte do poder público só vai acontecer quando o turismo adquirir (realmente) importância na política local. Segundo, que pode não ter havido um trabalho efetivo por parte dos atores ou agentes nesse sentido, para estabelecimento de convênios ou elaboração de contratos que viabilizassem a liberação de mais recursos.

Mesmo na hipótese de nenhum movimento em prol da priorização dos problemas detectados no Estudo ter ocorrido de forma sistemática e consistente, ou seja, de nenhum dos problemas dos 65 destinos ter sido valorizado, a ponto de merecer um programa mais específico mesmo dentro do PNT, de metas amplas, não se pode deixar de considerar a atuação de agentes nesse processo. Lembre-se que a liberação de recursos ocorre por meio de instrumentos como celebração de convênios e elaboração de contratos. Em outras palavras, a liberação de recursos ocorre sob provocação de agentes/atores. Ou, conforme Serra e Paz (2020), existe uma relação Estado-agentes do turismo-território, que evidencia a forma como se desenvolve o turismo.

São feitas algumas considerações para tentar elucidar a função de agentes ou atores nesse sentido: Souza (2006) afirma que o papel dos governos em políticas e programas não está reduzido nem foi empiricamente comprovado, como se comenta. Lima e D’Ascenzi (2013) corroboram esta afirmação e alertam para a necessidade de entendimento das especificidades dos processos de implementação e o papel dos burocratas. Outros segmentos, afora os governos, se envolvem em programas ou políticas. É o caso dos grupos de interesse e dos movimentos sociais, que interferem no processo com maior ou menor influência, conforme as coalizões do governo. 
Sobre o papel dos governos, Vieira (2011) lembra que há debilidade na gestão local e que isso pode impedir a execução de ações do turismo, desde seu planejamento. Arretche (2006) refere que há dificuldades em níveis estaduais e municipais na implementação de programas, como a baixa capacidade institucional e gerencial; há menos capacidade de mobilização de recursos e o próprio limite de atuação. Costa (2002) afirma que a implementação de programas expõe a precariedade generalizada no processo, a começar pelas informações, definições dos problemas e outros.

Sobre os grupos de interesse, Viana (1996) explica que eles são não-oficiais, representados por partidos políticos (interesses agregados), indivíduos simples com direito de serem ouvidos e os oficiails, com a obrigação de ouvir. Frey (2009) produz reflexões relevantes neste sentido, pois afirma que a dinâmica que envolve os grupos de interesse não é estática, e suas configurações e interações podem se transformar significativamente de acordo com a mudança de percepção dos atores envolvidos.

Hussein (2018) se aprofunda ainda mais na temática e apresenta uma perspectiva atual dos desafios no desenvolvimento e implantação de políticas públicas na República do Malawi, demonstrando que existem muitos fatores, além dos políticos, que influenciam a implementação de políticas públicas. Dois fatores elencados neste rol são a falta de pessoal qualificado para efetiva implementação destas políticas, e a quantidade de recursos financeiros suficientes para a efetiva implementação destas políticas.

A liberação de recursos, que representa a solução dos problemas detectados ou etapa de implementação de programas, ainda está envolta em outras questões, que esbarram na efetividade da burocracia estatal brasileira, que nem sempre possui a estrutura adequada para atender a um conjunto amplo de demandas.

Como o quadro de liberação de recursos para os 65 destinos é amplo e não foram identificados programas ou políticas específicas relativas a ela (como dito), entende-se que cada caso (como os quatro destinos selecionados para esta pesquisa) deve ser visto em suas particularidades e dentro das premissas teóricas relativas ao assunto. 


\subsection{Panorama dos 65 destinos indutores}

O panorama dos 65 destinos indutores pode ser observado na tabela 2 , onde se encontra a pontuação atribuída a cada um dos 65 destinos turísticos no "Estudo de Competitividade" de 2008. O índice geral resume a pontuação de cada uma das três dimensões avaliadas pelo Estudo - modelo de regulação, ambiente de negócios e infraestrutura e recursos humanos, naturais e culturais - as quais, por sua vez, englobam 13 dimensões constitutivas do indicador de competitividade: políticas públicas e regulamentações; legislação ambiental; segurança; saúde e higiene; priorização do setor de turismo; infraestrutura aérea; infraestrutura de transporte terrestre; infraestrutura de turismo; infraestrutura de comunicação; preços no setor de turismo; recursos humanos; percepção nacional sobre o turismo e recursos naturais e culturais.

Esse indicador foi especialmente construído pelos consultores representantes do MTur, FGV e SEBRAE, órgãos parceiros realizadores da pesquisa. Sobre a metodologia do Estudo, foi utilizada a metodologia da pontuação, a qual permitiria identificar os pontos fortes e os pontos fracos de cada destino, bem como seu posicionamento relativo ante os demais. Esse quadro iria servir de "subsídio para o estabelecimento de políticas públicas de alocação de recursos para consolidação do processo de competitividade dos destinos em questão" (MTur, 2008, p. 31). 
Tabela 2: Pontuação dos destinos turísticos segundo Estudo de Competitividade

\begin{tabular}{|c|c|c|c|c|c|}
\hline 2008 & Tipo & $\begin{array}{l}\text { Índice } \\
\text { Geral }\end{array}$ & 2008 & Tipo & $\begin{array}{l}\text { Índice } \\
\text { Geral }\end{array}$ \\
\hline Alto Paraíso de Goiás & Não Capital & 41,4 & Maceió & Capital & 55,9 \\
\hline Angra dos Reis & Não Capital & 56,0 & Manaus & Capital & 63,8 \\
\hline Aracaju & Capital & 52,4 & Maragogi & Não Capital & 44,0 \\
\hline Aracati & Não Capital & 39,7 & Maraú & Não Capital & 41,4 \\
\hline Armação dos Búzios & Não Capital & 46,2 & Mata de São João & Não Capital & 44,7 \\
\hline Balneário Camboriú & Não Capital & 63,4 & Mateiros & Não Capital & 29,3 \\
\hline Barcelos & Não Capital & 34,9 & Natal & Capital & 59,2 \\
\hline Barreirinhas & Não Capital & 40,1 & Nova Olinda & Não Capital & 31,6 \\
\hline Belém & Capital & 63,7 & Ouro Preto & Não Capital & 62,6 \\
\hline Belo Horizonte & Capital & 69,0 & Palmas & Capital & 47,2 \\
\hline Bento Gonçalves & Não Capital & 59,3 & Paranaguá & Não Capital & 54,0 \\
\hline Boa Vista & Capital & 52,0 & Paraty & Não Capital & 44,6 \\
\hline Bonito & Não Capital & 44,5 & Parintins & Não Capital & 45,4 \\
\hline Brasília & Capital & 65,7 & Parnaíba & Não Capital & 41,2 \\
\hline Cáceres & Não Capital & 48,0 & Petrópolis & Não Capital & 56,7 \\
\hline Caldas Novas & Não Capital & 49,9 & Pirenópolis & Não Capital & 52,7 \\
\hline Campo Grande & Capital & 50,8 & Porto Alegre & Capital & 63,6 \\
\hline Corumbá & Não Capital & 48,0 & Porto Seguro & Não Capital & 59,1 \\
\hline Cuiabá & Capital & 59,2 & Porto Velho & Capital & 42,8 \\
\hline Curitiba & Capital & 66,2 & Recife & Capital & 70,9 \\
\hline Diamantina & Não Capital & 54,3 & Rio Branco & Capital & 46,6 \\
\hline Fernando de Noronha & Não Capital & 46,9 & Rio de Janeiro & Capital & 69,7 \\
\hline Florianópolis & Capital & 62,9 & Salvador & Capital & 72,8 \\
\hline Fortaleza & Capital & 60,6 & Santarém & Não Capital & 49,6 \\
\hline Foz do Iguaçu & Não Capital & 66,3 & São Joaquim & Não Capital & 37,8 \\
\hline Goiânia & Capital & 60,6 & São Luís & Capital & 57,4 \\
\hline Gramado & Não Capital & 55,2 & São Paulo & Capital & 72,0 \\
\hline Ilhabela & Não Capital & 52,3 & S Raimundo Nonato & Não Capital & 34,0 \\
\hline Ipojuca & Não Capital & 37,9 & Teresina & Capital & 45,7 \\
\hline Jijoca de Jericoacoara & Não Capital & 33,3 & Tibau do Sul & Não Capital & 39,4 \\
\hline João Pessoa & Capital & 67,7 & Tiradentes & Não Capital & 45,3 \\
\hline Lençóis & Não Capital & 49,9 & Vitória & Capital & 61,4 \\
\hline Macapá & Capital & 47,7 & & & \\
\hline Brasil & & 52,0 & & & \\
\hline Capital & & 59,3 & & & \\
\hline Não Capital & & 46,7 & & & \\
\hline
\end{tabular}


Por essa tabela 2, vê-se que os destinos turísticos com melhor pontuação relativa à competitividade, bem como os de menor pontuação, encontram-se distribuídos nas cinco regiões, entre capitais e não capitais e entre os vários tipos de atividade turística. A falta de concentração dessa pontuação (maior ou menor) em uma região ou em uma atividade turística específica significa que há deficiências generalizadas no desenvolvimento do turismo no Brasil, tanto nas capitais como nas não capitais. Não se trata, pois, de eficiências pontuais, típicas do lugar ou do desenvolvimento de uma atividade turística específica.

Tais deficiências podem ser relacionadas com as vantagens comparativas (recursos naturais: clima, paisagem, flora, fauna) ou com as vantagens competitivas (infraestrutura de turismo: hotéis, atrações, rede de transporte; festivais e eventos; qualidade de administração etc), citadas por Dwyer e Kim (2003), ou ainda com as duas juntas.

Como o resultado final apresentado na tabela é somatório da pontuação de cada pilar, não se pode, por exemplo, entender que metade da pontuação máxima (10) corresponda a uma vantagem e outra metade à outra. Até porque, cada pilar avaliado tinha um peso que levava em conta variáveis, dimensões e sua contribuição para o índice geral de competitividade (MTur, 2008), ou seja, cada pilar tinha um peso específico.

Crouch e Ritchie (1999) justificam que a competitividade dos destinos turísticos tem mais complicações que a avaliação desse fenômeno em outro setor da economia. Essas complicações são representadas por aspectos que os analistas utilizam na avaliação, conforme sua perspectiva sobre o que está sendo avaliado.

Além disso, conforme Vasconcelos e Cyrino (2000), as competências (ou pilares) têm importância relativa dentro da vantagem competitiva. É o que acontece, por exemplo, na abordagem da competitividade com base nas habilidades de construção e de reconfiguração de recursos para lidar melhor com o ambiente (capacidades) (Justa, 2008).

Os destinos selecionados neste estudo, Ouro Preto, Rio Branco, São Joaquim e Goiânia, representam quatro regiões geográficas do país, fornecendo um panorama geral para os destinos indutores regionais. Além disso, encontram-se entre os de pontuação média e pontuação inferior, capitais e não capitais. Para tanto, considerou-se que destinos com esses níveis de pontuação mereceriam providências mais urgentes, a fim de melhorarem suas condições de competitividade até frente aos demais destinos abrangidos pelo Estudo. 
Na tabela 3, percebe-se que 37 destinos receberam mais recursos após o "Estudo de Competitividade", enquanto 28 receberam menos. Considerando a quantidade de convênios e contratos de repasses, 32 destinos assinaram mais após o Estudo; cinco mantiveram o número, e 28 assinaram menos convênios. Houve um total de 639 entre convênios e termos de parceria firmados em 2009/2010, contra 571, em 2006/2007, numa diferença de 68 projetos.

No total de recursos recebidos, houve um crescimento de $35,43 \%$, totalizando $\mathrm{R} \$$ 766.424.26039 no biênio 2009/2010, contra R\$ 565.919.248,30 do biênio 2006/2007.

Tabela 3 - Repasse de recursos aos destinos antes e após o Estudo de Competitividade

\begin{tabular}{|c|c|c|c|c|c|c|}
\hline Cidade & $\begin{array}{l}\text { Vol rec-R\$ } \\
2006 / 2007\end{array}$ & $\begin{array}{l}\text { Vol rec-R\$ } \\
2009 / 2010\end{array}$ & $\begin{array}{c}\text { Variação } \\
\%\end{array}$ & $\begin{array}{l}\text { Conv/Parc } \\
2006 / 2007\end{array}$ & $\begin{array}{l}\text { Conv/Parc } \\
2009 / 2010\end{array}$ & Var. \\
\hline Aracati & $10.945 .000,00$ & $\mathbf{7 5 0 . 7 3 0 , 0 0}$ & $-93,14$ & 6 & 4 & 2 \\
\hline Belo Horizonte & $6.057 .306,00$ & $28.375 .830,00$ & 368,46 & 27 & 26 & -1 \\
\hline Fern. de Noronha & $95.040,00$ & 1,00 & $-100,00$ & 1 & 0 & -1 \\
\hline Goiânia & $13.401 .391,00$ & 45.892.964,00 & 242,45 & 31 & 23 & -8 \\
\hline Ipojuca & 413.554,00 & 1,00 & $-100,00$ & 1 & 0 & -1 \\
\hline Ouro Preto & $5.689 .760,00$ & $1.475 .000,00$ & $-74,08$ & 6 & 3 & -3 \\
\hline Rio Branco & $6.722 .216,22$ & $1.005 .790,00$ & $-85,04$ & 6 & 6 & 0 \\
\hline Rio de Janeiro & $15.444 .698,97$ & $61.452 .292,84$ & 297,89 & 47 & 28 & -19 \\
\hline São Joaquim & $860.000,00$ & $1.583 .750,00$ & 84,16 & 2 & 5 & 3 \\
\hline São Raim. Nonato & $270.000,00$ & $20.100 .000,00$ & 7344,44 & 2 & 2 & 0 \\
\hline Tibau do Sul & 1,00 & 693.069,85 & 69306885,00 & 0 & 3 & 3 \\
\hline
\end{tabular}

Fonte: Adaptado pelo pesquisador do Portal da Transparência (2015)

Nota. Verde, os quatro destinos selecionados para este trabalho; fundo amarelo, variações negativas no repasse.

Analisando a tabela 2 e 3, pode-se visualizar que destinos indutores com índices mais baixos de competitividade, como Tibau do Sul, obtiveram um aumento de recursos após o Estudo de Competitividade, mas esse não foi um padrão como pode ser visto no exemplo de Aracati, entre outros.

Este fato pode demonstrar que, quantitativamente, a liberação de recursos para mais ou para menos não atendeu a uma lógica de maior ou de menor necessidade demonstrada pela pontuação de competitividade no Estudo. Qualitativamente, a questão que fundamentou o PNT foi tornar os 65 destinos com melhores condições de competir. Logo, 
em princípio, todos estavam nas mesmas condições de recebimento de recursos por parte do MTur. Assim, esse entendimento representa que a finalidade do PNT não foi cumprida, pelo menos integralmente.

Ao mesmo tempo, como não se identificou a criação de nenhum programa ou plano especial posteriormente ao "Estudo de Competitividade", entende-se que a liberação de recursos para esses destinos estava atrelada ao PNT, tal como estão os destinos que não integram o grupo dos 65 (tabela 2).

Com isso, depreende-se que não houve tratamento diferenciado na política do MTur para os 65 destinos em relação aos demais, já que, pelos documentos pesquisados, os problemas detectados no Estudo não integraram nenhuma pauta especial, programa ou agenda de política do órgão.

\subsection{Ouro Preto}

Não capital, localizada na região Sudeste, com 62,6 pontos no índice geral de competitividade no Estudo de 2008. A variação do recebimento de recursos em relação ao biênio 2006/2007 foi negativa (- 74\%).

Ouro Preto é patrimônio histórico e cultural da humanidade desde 1980 e possui o maior acervo arquitetônico do país. Rica em vantagens comparativas (montanhas, nascentes) e em vantagens competitivas (igrejas, museus, chafariz e outros pontos turísticos), seus principais tipos de turismo são o cultural, o histórico e o arquitetônico.

Nos anos posteriores ao Estudo, 2008, a cidade teve seus indicadores individuais de competitividade nas 13 dimensões de avaliação modificadas da seguinte forma, em relação aos recursos recebidos (tabela 4): 
Tabela 4 - Dimensões de avaliação Ouro Preto

\begin{tabular}{llllllll}
\hline Ouro Preto & Índ. Geral & $\begin{array}{l}\text { Infra. } \\
\text { Geral }\end{array}$ & Aces. & $\begin{array}{l}\text { Serv. } \\
\text { Eq. Tur. }\end{array}$ & $\begin{array}{l}\text { Atrat. } \\
\text { Tur. }\end{array}$ & $\begin{array}{l}\text { Mark. } \\
\text { promo. } \\
\text { destino }\end{array}$ & Pol. Púb. \\
\hline 2008 & 62,6 & 59,2 & 51,1 & 45 & 75,7 & 75,8 & 66 \\
\hline 2009 & 64,3 & 64 & 57,8 & 45,4 & 74,8 & 71,8 & 67,8 \\
\hline 2010 & 67,2 & 60,5 & 61,7 & 47,8 & 76 & 71 & 65,4 \\
\hline $2010-2008$ & 4,6 & 1,3 & 10,6 & 2,8 & 0,3 & $-4,8$ & $-0,6$ \\
\hline RR (08-09-10) & & & $975.000,00$ & & $1.137 .929,00$ & & Aspec. \\
\hline \hline Ouro Preto & Coop. & Megional & Monit. & Ec. Local & Cap. & Aspec. & Aspec. \\
\hline 2008 & 68,3 & 58 & 48 & 60,2 & 63,9 & 66,1 & 85,4 \\
\hline 2009 & 70,7 & 59,3 & 52 & 60,3 & 70,6 & 68,4 & 79,1 \\
\hline 2010 & 77,6 & 64,3 & 62,1 & 67,5 & 77 & 69,9 & 83,5 \\
\hline $2010-2008$ & 9,3 & 6,3 & 14,1 & 7,3 & 13,1 & 3.8 & $-1,9$ \\
\hline RR (08-09-10 & & & & & & & Amb. \\
\hline
\end{tabular}

Fonte: Elaborada pelos autores com base nos dados da pesquisa

Ouro Preto apresentou três projetos no biênio e recebeu recursos para duas das 13 dimensões de competitividade do Estudo. Das duas, o acesso teve variação positiva de 10,6, passando de 51,1 para 61,7; a dimensão atrativos turísticos teve variação negativa de 0,3 pontos, passando de 75,7 para 76,0. Das dimensões que não receberam recursos, economia local teve a maior variação positiva, 14,1 pontos, e marketing apresentou a maior queda, 4,8 pontos. Atrativos turísticos foi o que mais recursos recebeu, $\mathrm{R} \$ 1.137 .929,00$.

Diante desses resultados, infere-se que a significativa variação negativa dos recursos em relação ao biênio anterior pode ter contribuído para a variação também negativa de indicadores, não se excluindo, desse entendimento, a referida afirmação de Souza (2006) de que pode haver rejeição e disputas nos processos de implementação de projetos.

Antes disso, porém, pode ter ocorrido (como em grande parte de outros dos 65 também pode) a pouca, inadequada ou nenhuma atuação dos grupos de interesse, além de uma aparente pouca atuação dos governos estaduais e municipais (atores oficiais), já que Ouro Preto é patrimônio histórico e cultural da humanidade. 


\subsection{Rio Branco}

Capital do Acre, na região Norte, com 46,6 pontos no índice geral do Estudo de 2008, abaixo da média do Brasil de 52,1 pontos. Entre as vantagens comparativas da região está a sustentabilidade - "90\% das florestas, rios e lagos do estado estão preservados e a área concentra a maior biodiversidade do planeta"- e entre as competitivas, estão a arquitetura histórica e a cultura. Porém, não há tanta procura por turistas (Destinos, 2015, s/p).

A variação dos recursos recebidos no biênio pós Estudo foi expressivamente negativa (-85\%) e sua aplicação foi nos seguintes pilares (tabela 5):

Tabela 5 - Dimensões de avaliação Rio Branco

\begin{tabular}{llllllll}
\hline \multirow{2}{*}{ Rio Branco } & $\begin{array}{l}\text { Índ. } \\
\text { Geral }\end{array}$ & $\begin{array}{l}\text { Infra. } \\
\text { Geral }\end{array}$ & Aces. & $\begin{array}{l}\text { Serv. Equip. } \\
\text { Tur. }\end{array}$ & Atrat. Tur. & $\begin{array}{l}\text { Mark. promo. } \\
\text { destino }\end{array}$ & Pol. Púb. \\
\hline 2008 & 46,6 & 63,5 & 57,2 & 36 & 45,6 & 15,4 & 50,1 \\
\hline 2009 & 49,3 & 59,2 & 62,1 & 41,6 & 46 & 20,5 & 53,9 \\
\hline 2010 & 52,9 & 61,7 & 66 & 48,5 & 48,2 & 20,5 & 50 \\
\hline $2010-2008$ & 6,3 & 1,8 & 8,8 & 12,5 & 2,6 & 5,1 & $-0,1$ \\
\hline RR(08-09-10) & & $263.250,00$ & & $195.000,00$ & $352.500,00$ & $368.695,00$ & $100.000,00$ \\
\hline \hline Rio Branco & Coop. & Monit. & Econ. & Capac. & Aspec. Soc. & Aspec. & Aspec. \\
\hline 2008 & Region. & Local & empres. & & Ambien. & Cult. \\
\hline 2009 & 38,3 & 7,4 & 68,5 & 49,6 & 54,6 & 60,7 & 45,2 \\
\hline 2010 & 38,8 & 9,8 & 73,5 & 51,7 & 60,9 & 62,9 & 46,9 \\
\hline $2010-2008$ & 4,4 & $-0,1$ & 7,6 & 10,2 & 9,1 & 72,1 & 54,7 \\
\hline RR(08-09-10) & & & & & 63,7 & 11,4 & 9,5 \\
\hline
\end{tabular}

Fonte: Elaborada pelos autores

Rio Branco apresentou seis projetos no biênio e recebeu recursos para 7 das 13 dimensões do Estudo. Dessas, serviços e equipamentos, atrativos turísticos, marketing, aspectos sociais, infraestrutura e aspectos culturais tiveram variação positiva no indicador. A dimensão serviços e equipamentos teve a maior variação positiva, passando de 36,0 para 48,5. A outra dimensão com recursos, políticas públicas, teve uma variação negativa. Políticas públicas passou de 50,1 para 50. Das dimensões que não receberam recursos, aspectos ambientais teve a maior variação positiva, passando de 60,7 para 72,1 e monitoramento foi a única queda, de 7,4 para 7,3. Marketing foi a que mais recebeu recursos, totalizando $\mathrm{R} \$ 368.695,00$. 
A variação negativa dos recursos recebidos (tal como em outros destinos analisados) pode ter contribuído para a não solução de todos os problemas detectados no Estudo. Dessa variação, infere-se uma pequena ou nenhuma atuação adequada dos atores envolvidos nas políticas de turismo. Pela importância do aspecto da sustentabilidade para o estado, entende-se que o poder público - atores oficiais - seria um dos maiores responsáveis pelo desenvolvimento da atividade turística na região.

Para Dwyer e Kim (2003), as condições da demanda/fluxo de turistas (com três principais elementos: percepção, preferências e consciência) representam um dos pontos de um destino turístico competitivo. Rio Branco conta com pouca afluência de turistas.

Aliás, esse dado demonstra o pouco ou inadequado trabalho de marketing do turismo desenvolvido no local, embora o pilar marketing tenha sido o que mais recebeu recursos.

\subsection{São Joaquim}

Não capital localizada em Santa Catarina, região Sul, com 37,8 pontos no índice geral do Estudo de 2008, abaixo da média do Brasil de 52,1 pontos. Os recursos recebidos variaram positivamente em 84,1\% em 2009/2010, em relação ao biênio anterior ao Estudo.

A cidade é considerada a mais fria do país. Tem o clima como principal vantagem comparativa. As festas temáticas e a agricultura são as vantagens competitivas mais destacadas. As principais atividades turísticas estão relacionadas com o turismo climático (outono climático), o cultural e o de negócios - a cidade é grande produtora de maçãs e de mel (Portal São Joaquim, 2018).

Os recursos recebidos foram aplicados nas dimensões de competitividade apresentados na tabela 10. 
Tabela 10 - Dimensões de avaliação de São Joaquim

\begin{tabular}{|c|c|c|c|c|c|c|c|}
\hline S Joaquim & $\begin{array}{l}\text { Índ. } \\
\text { Geral }\end{array}$ & $\begin{array}{l}\text { Infra. } \\
\text { Geral }\end{array}$ & Aces. & $\begin{array}{l}\text { Serv. } \\
\text { Equip. Tur. }\end{array}$ & $\begin{array}{l}\text { Atrat. } \\
\text { Tur. }\end{array}$ & $\begin{array}{l}\text { Mark. promo. } \\
\text { destino }\end{array}$ & Pol. Púb. \\
\hline 2008 & 37,8 & 66,8 & 48,6 & 25,9 & 44,8 & 22,4 & 38,2 \\
\hline 2009 & 39,8 & 67,8 & 50,8 & 28,4 & 45,3 & 29,5 & 41 \\
\hline 2010 & 41,7 & 71,8 & 55,4 & 26,2 & 49,9 & 35 & 35,9 \\
\hline $2010-2008$ & 3,9 & 5 & 6,8 & 0,3 & 5,1 & 12,6 & $-2,3$ \\
\hline $\mathrm{RR}(08-09-10)$ & & $\begin{array}{c}360.750,0 \\
0 \\
\end{array}$ & & $682.500,00$ & $\begin{array}{c}1.281 .498,8 \\
3 \\
\end{array}$ & & \\
\hline São Joaquim & $\begin{array}{l}\text { Coop. } \\
\text { Reg. }\end{array}$ & Monit. & $\begin{array}{l}\text { Econ. } \\
\text { Local }\end{array}$ & $\begin{array}{l}\text { Capac. } \\
\text { Empr. }\end{array}$ & Aspec. Soc. & Aspec. Amb. & Aspec. Cult. \\
\hline 2008 & 25,4 & 3 & 59 & 24,7 & 48 & 26,4 & 37 \\
\hline 2009 & 28,1 & 5,9 & 58,9 & 33,9 & 40,7 & 30 & 35,3 \\
\hline 2010 & 43 & 7,5 & 61,5 & 27,2 & 42,2 & 26,4 & 39,6 \\
\hline $2010-2008$ & 17,6 & 4,5 & 2,5 & 2,5 & $-5,8$ & 0 & 2.6 \\
\hline $\mathrm{RR}(08-09-10)$ & & & & & & & \\
\hline
\end{tabular}

Fonte: Elaborada pelos autores

São Joaquim apresentou cinco projetos no biênio e recebeu recursos para 3 das 13 dimensões indicativas de competitividade no Estudo de 2008. Das que receberam recurso, infraestrutura geral, serviços e equipamentos turísticos e atrativos turísticos apresentaram variação positiva após o Estudo. A dimensão Atrativos Turísticos foi o que alcançou a maior variação positiva, passando de 44,8 para 49,9. Das dimensões que não receberam recursos, todas tiveram variação positiva, sendo cooperação regional o que obteve a maior variação positiva, passando de 25,4 para 43,0. A dimensão atrativos turísticos foi o que mais recebeu recursos, $\mathrm{R} \$ 1.281 .498,83$.

Esses resultados, porém, apesar de positivos, possivelmente não foram suficientes para melhorar de forma significativa o indicador geral de sua competitividade $(37,8)$, avaliado pelo Estudo em 2008.

Um destino turístico, para ser competitivo, depende de três pontos fundamentais: gerenciamento dos fatores relacionados a ele (atividades do setor público e do privado), condições da demanda (percepção, preferências e consciência) e condições situacionais (econômica, social, cultural, política, legal). Esses pontos podem ser comparados para qualificar e ampliar os aspectos que determinam a destinação turística (Dwyer \& Kim, 2003). 
A situação de São Joaquim também indica uma tímida atuação dos atores ou falta de um planejamento estratégico do turismo.

\subsection{Goiânia}

Capital localizada na região Centro-Oeste, com pontuação de 60,6 no índice geral de competitividade segundo o Estudo de 2008. Esse indicador situa-se acima da média do Brasil de 52,1. Recebeu, no biênio posterior ao "Estudo de Competitividade", R\$̦ 45.892.964,00, representando uma variação positiva de $242,4 \%$ em relação aos recursos do biênio anterior. A capital e seu entorno contam com vantagens comparativas - cerrado bem preservado em algumas regiões, grande número de parques verdes - e vantagens competitivas - como centros culturais, museus e parques. O turismo desenvolvido é o ecológico, o histórico, o cultural e, em grande escala o turismo de negócios (PORTAL GOIÂNIA, 2020). Além disso, é uma das capitais mais arborizadas do Brasil, com acentuada preocupação com a preservação ambiental.

Nos anos posteriores ao Estudo, 2008, Goiânia teve seus indicadores individuais de competitividade nas 13 dimensões de avaliação modificados da seguinte forma, em relação aos recursos recebidos (tabela 11).

Goiânia apresentou 23 projetos para o turismo no biênio pós Estudo e recebeu recursos para 7 das 13 dimensões que compuseram o indicador de competitividade do Estudo. Das dimensões que receberam recursos, monitoramento e aspectos culturais tiveram variação negativa no índice, sendo aspectos culturais o pilar com a maior queda, passando de 70,4 pontos para 60,7. Das demais dimensões que receberam recursos, serviços e equipamentos, marketing, políticas públicas, atrativos turísticos e infraestrutura geral tiveram uma variação positiva no indicador. Políticas públicas foi a dimensão que teve a maior variação positiva de 14 pontos, passando de 57,6 para 71,6. Das dimensões que não receberam recursos, capacidade empresarial teve a maior variação positiva, passando de 76,5 para 89,8 pontos e aspectos sociais a maior queda, passando de 72,1 para 67,8. A dimensão serviços e equipamentos turísticos foi o que mais recebeu recursos, totalizando $\mathrm{R} \$ 61.666 .140,00$. 
Tabela 11: Dimensões de avaliação Goiânia

\begin{tabular}{|c|c|c|c|c|c|c|c|}
\hline Goiânia & $\begin{array}{l}\text { Índ. } \\
\text { Geral }\end{array}$ & $\begin{array}{l}\text { Infra. } \\
\text { Geral }\end{array}$ & Aces. & $\begin{array}{l}\text { Serv. e Eq. } \\
\text { Turísticos }\end{array}$ & Atrat. Tur. & $\begin{array}{l}\text { Mark. e } \\
\text { promo. } \\
\text { destino }\end{array}$ & Pol. Públ. \\
\hline $2008^{*}$ & 60,6 & 72,8 & 66,7 & 57,8 & 48,7 & 21,4 & 57,6 \\
\hline 2009 & 62,6 & 73,8 & 69,8 & 60,3 & 49,1 & 25,4 & 64,9 \\
\hline 2010 & 65,1 & 77,9 & 70,1 & 60,7 & 51,5 & 28,1 & 71,6 \\
\hline $2010-2008$ & 4,5 & 5,1 & 3,4 & 2,9 & 2,8 & 6,7 & 14 \\
\hline$R R(08$ A 10) & & $38.577 .447,94$ & & $61.666 .140,00$ & $8.218 .858,51$ & $1.359 .996,94$ & $591.980,00$ \\
\hline Goiânia & $\begin{array}{c}\text { Coop. } \\
\text { Regio } \\
\text { nal }\end{array}$ & Monit. & $\begin{array}{l}\text { Econ. } \\
\text { Local }\end{array}$ & Capac. Empres. & Aspec. Sociais & $\begin{array}{c}\text { Aspec. } \\
\text { Ambient }\end{array}$ & $\begin{array}{l}\text { Aspec. } \\
\text { Culturais }\end{array}$ \\
\hline 2008 & 64,8 & 43,3 & 62 & 76,5 & 72,1 & 68,4 & 70,4 \\
\hline 2009 & 67,2 & 35,7 & 64,6 & 86,5 & 69,4 & 72,7 & 66,1 \\
\hline 2010 & 73,3 & 41,3 & 73 & 89,8 & 67,8 & 76,3 & 60,7 \\
\hline $2010-2008$ & 8,5 & -2 & 11 & 13,3 & $-4,3$ & 7,9 & $-9,7$ \\
\hline$R R(08-09-10)$ & & $2.080 .100,00$ & & & & & $783.000,00$ \\
\hline
\end{tabular}

Fonte: Elaborada pelos autores

* Ano de partida da comparação

Por esse resultado, depreende-se que o objetivo do PNT não se concretizou integralmente em Goiânia, haja vista a variação negativa dos indicadores monitoramento e aspectos culturais (que contaram com recursos), mesmo com o fator peso influenciando a avaliação de cada dimensão.

\section{Conclusão}

O desenvolvimento do tema turismo e competitividade na perspectiva acadêmica trouxe, para além dos objetivos deste trabalho, a oportunidade de comprovar a complexidade do ambiente político das respectivas áreas envolvidas (como o ciclo das políticas públicas, em especial a construção da agenda e a implementação) e a complexidade de mensuração da competitividade com base em indicadores específicos.

Está claro, na análise dos documentos que o MTur elaborou, seu planejamento através dos Planos Nacionais publicados, muito especialmente o de 2007/2010, que estabelecia um 
recorte claro em 65 destinos que deveriam ser priorizados. Está claro, também, que a realização do Estudo de Competitividade dá sequência a essa política, com o índice de competitividade passando a funcionar como diagnóstico, apontando com clareza onde existiam fragilidades e que pilares deveriam receber mais recursos.

O índice de competitividade da forma como foi concebido é também um avaliador das políticas, pois o aumento desse índice nos destinos turísticos pode representar um acerto nos recursos investidos. Mas o êxito termina aqui e outros fatores, como já apontados, influenciam o ciclo de políticas públicas na fase de implementação, fazendo com que os objetivos e os resultados não estejam concatenados.

Ficou claro ainda, nos resultados, que após a publicação do Estudo, não houve um maior direcionamento de recursos para os destinos prioritários, assim como esses destinos não estão presentes majoritariamente entre os que mais receberam recursos.

Independente do montante de recursos distribuídos, fica evidente que para melhorar a condição das 13 dimensões da competitividade avaliadas em 2008, dois anos não seriam insuficientes. O PNT, publicado em 2007, deu prazo para os 65 destinos até final de 2010, para que solucionassem as questões referentes às dimensões do indicador, porém, sem considerar as peculiaridades de cada um, a burocracia, e a complexidade da política.

Porém, esses destinos não foram selecionados ou indicados no documento do PNT. A conclusão é de que os problemas encontrados nas 13 dimensões dos 65 destinos objeto do "Estudo de Competitividade" se mantiveram no mesmo patamar dos problemas gerais do país, ou seja, dentro da perspectiva ampla de ação do PNT 2007/2010.

Desta forma, ficou evidente que há uma falta de lógica entre a aplicação dos recursos e a necessidade apontada no Estudo, assim como o volume de investimento feito e os resultados dos destinos, no entanto o Modelo do Índice de Competitividade Turística foi reconhecido como um avanço pelos técnicos e acadêmicos do setor.

Em síntese, as ações de liberação de recursos pelo MTur para os 65 destinos turísticos não foram alinhadas nem ao objetivo temporal estabelecido no PNT para a estruturação de tais destinos, nem à indicação deles, de suas dimensões competitivas e das necessidades para a solução pelo "Estudo de Competitividade" de 2008. Este fato demonstra que a estratégia 
inicial não foi efetivamente seguida, e como consequência das descontinuidades no Mtur, também ocorreram descontinuidades na própria estratégia.

Gerencialmente, os resultados desta pesquisa demonstram a necessidade de uma melhor concatenação entre os elementos definidores de projetos de execução pública e a realidade objeto dos projetos. Uma sugestão de estudos futuros é a realização de pesquisa qualitativa, com entrevistas e levantamentos com gestores públicos e especialistas em Gestão Municipal para que se identifique as barreiras que impedem a maior efetividade na realização de projetos.

\section{Referências}

Alvarenga, M. A., Leite, N. R. P., de Freitas, A. D. G., \& Ruas, R. L. (2017). Capacidades dinâmicas e vantagem competitiva em ambientes de mudanças constantes, à luz da análise do filme 'Recém-chegada'. REGE-Revista de Gestão, 24(1), 35-44. doi: 10.1016/j.rege.2016.06.010

Amaral Filho, J. do. (2001). A endogeneização no desenvolvimento econômico regional e local. Planejamento e Políticas Públicas, 23, 261-286. Recuperado de: https://www.ipea.gov.br/ppp/index.php/PPP/article/viewFile/78/89.

Armenski, T., Marković, V., Davidović, N., \& Jovanović, T. (2011). Integrated model of destination competitiveness. Geographica Pannonica, 15(2), 58-69. Recuperado de: https://www.dgt.uns.ac.rs/pannonica/papers/volume15 2 2 4.pdf.

Arretche, M. (2006). Mitos da descentralização: mais democracia e eficiência nas políticas públicas? Revista Brasileira de Ciências Sociais, 31.

BBC Brasil. (2011). Brasil perde posições em ranking mundial do turismo. Recuperado de: http://www.bbc.com/portuguese/noticias/2011/03/110307 turismo ranking pu.shtml.

Borges, A. L. M., Ferreira, L. D. de O., \& Nóbrega, W. R. de M. (2019). Políticas públicas de revitalização urbana: uma abordagem no turismo e lazer das cidades de Natal/RN e Recife/PE. Novos Cadernos NAEA, 22(3), 219244. Recuperado de: https://periodicos.ufpa.br/index.php/ncn/article/view/7092/5815.

Costa, B. L. D. (2002). As mudanças na agenda das políticas sociais no Brasil e os desafios da inovação. In: A. Carvalho, F. Salles, M. Guimarães, \& W. Ude. (Org.). Políticas públicas. Belo Horizonte: UFMG.

Crouch, G. I., \& Ritchie, J. B. (1999). Tourism, competitiveness, and societal prosperity. Journal of business research, 44(3), 137-152. doi: 10.1016/S0148-2963(97)00196-3

Damas, M. T., \& Brambatti, L. E. (2019). O Planejamento turístico sob o viés de planos e programas: O caso do destino turístico Paranaguá-PR. RITUR-Revista Iberoamericana de Turismo, 9(2), 164-190. doi: 10.2436/20.8070.01.158

Destinos. (2015). Viagem destinos nacionais. Recuperado de: http://viagem.uol.com.br/guia/_brasil/riobranco/.

Dwyer, L., \& Kim, C. (2003). Destination competitiveness: determinants and indicators. Current issues in tourism, 6(5), 369-414. doi: 10.1080/13683500308667962

Fratucci, A. C., \& Moraes, C. C. de A. (2020). Inventário da oferta turística: reflexões teóricas para o planejamento e ordenamento do espaço turístico. Caderno Virtual de Turismo, 20(1). doi: 10.18472 /cvt.20n1.2020.1783 
Frey, K. (2009). Políticas públicas: um debate conceitual e reflexões referentes à prática da análise de políticas públicas no Brasil. Planejamento e políticas públicas, 21, 2009, 211-259.

Gooroochurn, N., \& Sugiyarto, G. (2004). Measuring competitiveness in the travel and tourism industry. University of Nottingham, Christel DeHaan Tourism and Travel Research Institute.

Hassan, S. S. (2000). Determinants of market competitiveness in an environmentally sustainable tourism industry. Journal of travel research, 38(3), 239-245. doi: 10.1177/004728750003800305

Hussein, M. K. (2018). The challenges facing development policy and projects implementation in Malawi. The $3^{\text {rd }}$. Annual International Conference on Public Administration and Development Alternatives (IPADA). 04-06 July, Stellenbosch University, Saldahna Bay, South Africa.

Justa, R. P. (2008). Modelo de avaliação competitiva de destinos turísticos com base nas capacidades dinâmicas (Dissertação de Mestrado em Administração Pública, Fundação Getúlio Vargas/Escola Brasileira de Administração Pública e de Empresas) Rio de Janeiro.

Lasswell, H. D. (1936). Certain prognostic changes during trial (psychoanalytic) interviews. Psychoanalytic Review, 23(3), 241-247.

Lima, L. L.; D'Ascenzi, L. (2013). Implementação de políticas públicas: perspectivas analíticas. Revista de sociologia e política, 21(48), 101-110. Recuperado de https://revistas.ufpr.br/rsp/article/view/38765/23651.

Melian-Gonzalez, A., \& García-Falcón, J. M. (2003). Competitive potential of tourism in destinations. Annals of Tourism Research, 30(3), 720-740. doi: 10.1016/S0160-7383(03)00047-1

Moyano, C. A. M., Lengler, J. F. B., \& Angnes, D. L. (2018). Matriz estratégica de marketing para agências de turismo. Revista Acadêmica Observatório de Inovação do Turismo 12(2), 93-113. Recuperado de: http://publicacoes.unigranrio.edu.br/index.php/raoit/article/view/5118/2750

MTur. Ministério do Turismo. (2008). Estudo de competitividade dos 65 destinos indutores do desenvolvimento turístico regional. Brasília: MTur.

MTur. Ministério do Turismo. (2008b). Dados e Fatos. Relatório Individual por Destino Turístico. Brasília: MTur. Recuperado de: http://www.turismo.gov.br/assuntos/6083-relat\%C3\%B3rio-individual-por-destinotur\%C3\%ADstico-2012.html

Oliveira, C. T. F., Zouain, D. M., Souza, L. A. V., \& Duarte, A. L. F. (2019). Competitiveness of tourist destinations: demand and performance factors. Tourism \& Management Studies, 15(4), 17-26. doi: 10.18089/tms.2019.150402

Pimentel, M. P. C., \& Pimentel, T. D. (2019). Avaliação política da política de estado de turismo de Minas Gerais. Revista Acadêmica Observatório de Inovação do Turismo, 13(1), 131-157. Recuperado de: http://publicacoes.unigranrio.edu.br/index.php/raoit/article/view/5192

Portal da Transparência. (2015). Recuperado de: http://transparencia.gov.br/.

PORTAL GOIÂNIA. (2020). Recuperado de: www.goiania.go.gov.br.

Portal São Joaquim. (2018). Município de São Joaquim. Recuperado de: http://turismo.saojoaquim.sc.gov.br/.

Rodrigues, M. M. A. (2011). Políticas Públicas (Coleção Folha Explica). São Paulo: Publifolha.

Ribeiro, J. \& Chamusca, P. (2020). Governança territorial, Atores e Desenvolvimento: um estudo sobre a organização territorial do cluster do calçado português. Revista de Geografia e Ordenamento do Território (GOT), 19, 186-217. doi: 10.17127/got/2020.19.008

Serra, H. R. H., \& Paz, I. R. (2020). O programa Mapa do Turismo Brasileiro e sua espacialidade no município de Marabá-PA. Caminhos de Geografia, 21(77), 193-208. doi: $\underline{10.14393 / R C G 217752730}$

Sette, I. R., \& Tomazzoni, E. L. (2017). Os desafios, as limitações e as perspectivas do modelo do Índice de Competitividade Turística no contexto da política nacional de turismo brasileira. Turismo-Visão e Ação, 19(2), 292-318. doi: 10.14210/rtva.v18n2.p292-318

Simon, H. A. (1957). Models of man: social and rational: mathematical essays on rational human behavior in society setting. New York: Wiley. 
Souza, C. (2006). Políticas públicas: uma revisão da literatura. Sociologias, 8(16), 20-45. doi: 10.1590/S1517$\underline{45222006000200003}$

Vasconcelos, F. C., \& Cyrino, Á. B. (2000). Vantagem competitiva: os modelos teóricos atuais ea convergência entre estratégia e teoria organizacional. Revista de Administração de empresas, 40(4), 20-37. doi: $\underline{10.1590 / \text { S0034-75902000000400003 }}$

Viana, A. L. (1996). Abordagens metodológicas em políticas públicas. Revista de administração pública, 30(2), 5-43. Recuperado de: http://bibliotecadigital.fgv.br/ojs/index.php/rap/article/view/8095/6917.

Vieira, A. R. M. (2011). Planejamento e Políticas Públicas de Turismo: análise dos módulos operacionais do Programa de Regionalização do Turismo no Pólo São Luis - MA. (Dissertação de Mestrado, Universidade de Brasília, Centro de Excelência em Turismo), Brasília-DF.

Vieira, D. P., Hoffmann, V. E., \& Alberton, A. (2018). Investimentos públicos, competitividade e desenvolvimento: um estudo em destinos turísticos brasileiros. Revista de Administração Pública, 52(5), 899917. doi: $10.1590 / 0034-7612174959$

Yin, R. K. (2015). Estudo de Caso: Planejamento e Método. 5. ed. Porto Alegre: Bookman. 